\title{
Epidemiology of tuberculosis and treatment outcomes among children in Pakistan: A 5 year retrospective study
}

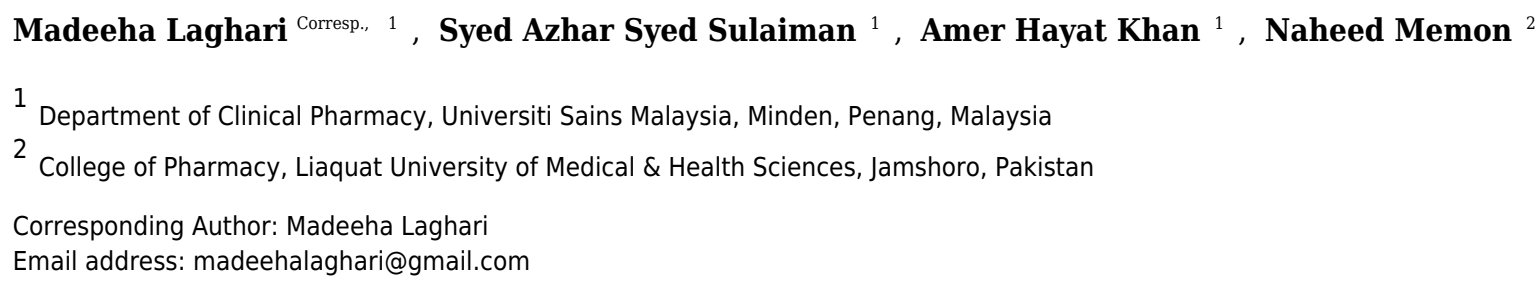

Background: Regardless of the advancement in medical technologies, the diagnosis of tuberculosis (TB) in children has remained a challenge. Childhood TB is rampant and an important cause of morbidity and mortality. The objective of this study was to determine the trend of TB and treatment outcomes in children aged $\leq 14$ years registered for TB treatment under DOTS course in 3 districts of Sindh, Pakistan. Methods: For this retrospective study, records of TB children ( $\leq 14$ years) registered for the treatment of TB from January 2011 to December 2015 in 3 districts of Pakistan, were collected.

Demographic data, baseline weight, clinical manifestations, radiography, histopathology results and treatment outcomes were collected from TB unit registers. Results: A total of 2,167 children were treated for TB during the study period. Of these, 1,199 (55.3\%) were females and 1,242 (57.3\%) were from urban areas. Over three-quarter of patients (76.9\%) had pulmonary TB with $13.3 \%$ of sputum smear positive cases. The overall treatment success rate was $92.4 \%$. In multivariate analysis, rural residents (OR: $2.146, p<0.001$ ), sputum smear positive cases (OR: 3.409, p < 0.001) and re-treated patients (OR: 5.919, p $<0.001$ ), were significantly associated with unsuccessful treatment outcomes. However, age group $\leq 2$ years, male and those who were underweight were found to have the highest risk of pulmonary tuberculosis (OR: 1.953, $p<0.001$; OR: 1.262, p =0.028; OR: $1.342, p=0.008)$, respectively. Conclusion: Patients at risk of treatment failure must be given particular attention. Moreover, strategies are needed to further improve the diagnosis and treatment of TB among children and improve the recording system. 
1

2

3

4

5

6 Madeeha Laghari $^{1 *}$, Syed Azhar Syed Sulaiman ${ }^{1}$, Amer Hayat Khan ${ }^{1}$, Naheed Memon ${ }^{2}$

$7 \quad{ }^{1}$ Department of Clinical Pharmacy, Universiti Sains Malaysia, Minden Penang, Malaysia

$8{ }^{2}$ College of Pharmacy, Liaquat University of Medical and Health Sciences, Jamshoro, Pakistan

*Corresponding author: madeehalaghari@gmail.com

12

13 
24 ABSTRACT

25

26

27

Background: Regardless of the advancement in medical technologies, the diagnosis of tuberculosis (TB) in children has remained a challenge. Childhood TB is rampant and an important cause of morbidity and mortality. The objective of this study was to determine the trend of TB and treatment outcomes in children aged $\leq 14$ years registered for TB treatment under DOTS course in 3 districts of Sindh, Pakistan.

Methods: For this retrospective study, records of TB children ( $\leq 14$ years) registered for the treatment of TB from January 2011 to December 2015 in 3 districts of Pakistan, were collected. Demographic data, baseline weight, clinical manifestations, radiography, histopathology results and treatment outcomes were collected from TB unit registers.

Results: A total of 2,167 children were treated for TB during the study period. Of these, 1,199 $(55.3 \%)$ were females and $1,242(57.3 \%)$ were from urban areas. Over three-quarter of patients (76.9\%) had pulmonary TB with $13.3 \%$ of sputum smear positive cases. In multivariate analysis, rural residents (OR: 2.146, $\mathrm{p}<0.001)$, sputum smear positive cases (OR: 3.409, p < 0.001) and re-treated patients (OR: 5.919, $\mathrm{p}<0.001$ ), were significantly associated with unsuccessful treatment outcomes. However, age group $\leq 2$ years, male and those who were underweight were found to have the highest risk of pulmonary tuberculosis (OR: 1.953, p $<0.001$; OR: 1.262, $\mathrm{p}=$ 0.028; OR: $1.342, \mathrm{p}=0.008)$, respectively.

Conclusion: The overall treatment success rate was $92.4 \%$. Patients at risk of treatment failure must be given particular attention. Moreover, strategies are needed to further improve the diagnosis and treatment of TB among children and improve the recording system. 


\section{BACKGROUND}

50

51

Tuberculosis (TB) is the $9^{\text {th }}$ leading cause of death at a global level, ranking higher than Human Immunodeficiency Virus/Acquired Immune Deficiency Syndrome (HIV/AIDS). During 2016, 10.4 million new TB cases were detected worldwide, of which $90 \%$ adults and $65 \%$ were male. During the same year, children aged $<15$ years comprised up to $6.9 \%$ of the notified new TB cases (WHO, 2017). According to a WHO report, a continuous rise has been seen in case detection rate of childhood TB worldwide with a parallel increase in the death toll of children with TB. In mathematical modelling study, it was estimated that 239,000 children died from TB in 2015 (Dodd et al., 2017).

Childhood TB has traditionally been unnoticed by practitioners, researchers, and experts partially, because of the notion that children are rarely infectious and therefore add little to the dissemination of disease (Adams et al., 2014). Without successful detection and treatment of TB infection both in adults and children, eradication strategies will be unproductive and attempts at epidemic TB control will be failed in future. This is because children present the repository for new cases to develop in future (Seddon \& Shingadia, 2014).

However, concern about childhood TB has increased significantly and in 2012, an annual WHO report included an estimation of childhood TB was included for the first time (WHO, 2012). Childhood TB is rampant and an important cause of morbidity and mortality in developing countries owing to poor socio-economic conditions, starvation, overcapacity, HIV 
68 co-infection (Glaziou et al., 2013) and the high prevalence of TB in adults contacts (Tilahun \& 69 Gebre-Selassie, 2016).

70

71

72

73

74

Pakistan stands among the eleven high TB burden countries and was one of the six countries that stands out as having the largest number of cases in 2014 (WHO, 2015). In 2016, of the total estimated incidence, 518,000 TB cases were notified in Pakistan, of which 51,000 were cases of children aged $\leq 14$ years. Pakistan together with India, Indonesia, China, and Philippines accounted for $56 \%$ of the global total incident cases in 2016 (WHO, 2017).

Sindh is a multicultural province of Pakistan and is portrayed by an extensive gap between rich and destitute individuals with unequal access to health services. Inhabitants of lowwage neighbourhoods, for instance, suffer from overcrowding and malnutrition. Consequently, they are susceptible to developing TB (Akhtar et al., 2007). In Pakistan, research contribution in childhood TB is still narrow and only few studies have been conducted until now. However, to the best of our knowledge this was the first study to discuss proportion of childhood TB cases treatment outcomes among children in Sindh province, particularly in studied districts.

The objectives of the study were to describe the trend of TB and treatment outcomes with the risks of treatment failure in children aged $\leq 14$ years.

\section{METHODS}

\section{Ethics approval and consent to participate}

Ethical approvals were issued by the relevant Institutional Research and Ethics Boards (IREBs) of Shah Bhitae Hospital Latifabad, Hyderabad Liaquat University Hospital Hyderabad / Jamshoro, Sindh Government Hospital Qasimabad, Hyderabad, Sayed Baqadar Shah Civil Hospital Matiari and Institute of chest diseases Kotri Sindh, Pakistan, (Vide Letter No: SBGH/L.ABAD HYD-1575; Dated: 13-04-17, LUH/Estt/-23176/14; Dated: 06-08-2016, MS- 
91 SGHQ/HYD/2187: Dated:13-04-17, CS/CH/MAT:1761; Dated:18-05-16 and ICDK/771; Dated:

92 12-04-17, respectively).

\section{Study design and data collection}

94 This was a retrospective study. Data was collected from January 2011 to December 2015 for

95

96

97

children suffering from TB and registered under DOTS. In order to determine the proportion of childhood cases, total TB cases including the numbers of adults were collected from TB registers. The registers contain information regarding the socio-demography (age, gender, and residence), clinical manifestations and laboratory examination (sputum or gastric aspirates microbiology, HIV status, radiography and histopathology results). All that information was transferred on a data collection form specially designed for the study. Patients were grouped as $\leq$ 2 years, 3 to 5 years, 6 to 10 years and 11 to 14 years. Body weight was calculated in percentiles using the data table of weight for age charts by Centres for Disease Control and Prevention (CDC). Patients with weight $<5$ percentiles were recorded as underweight and those with $\geq 95$ percentiles were considered as overweight (Centers for Disease Control and Prevention, 2001).

Children with TB are diagnosed and treated according to NTP under the DOTS strategy (Fig. 1). Each child with clinical symptoms including a cough lasting for $\geq 2$ weeks, fever, night sweats, dyspnoea and sputum production were examined. Assessment of nutritional status was done based on weight-for-age data from weight-for-age charts (Centers for Disease Control and Prevention, 2001). Children were diagnosed as having TB by considering suggestive clinical features, the history of contact, positive TST ( $\geq 10 \mathrm{~mm}$ was considered positive) (WHO, 2014), scoring charts (suggested by the Pakistan Paediatric Association) and evidence of TB in chest Xray (CXR) for pulmonary TB (PTB). Culture and Xpert MTB/RIF assays were used as add-on tests and specifically performed to exclude resistant TB. Furthermore, common forms of EPTB 
114 were diagnosed based on a positive result of an appropriate test: peripheral lymphadenitis: lymph

115 node biopsy or fine needle aspiration (FNAC); miliary TB: CXR; TB meningitis: lumbar

116 puncture with cerebrospinal fluid (CSF) analysis or cerebral computed Tomography (CT);

117 pleural effusion TB: CXR and pleural tap; abdominal TB: abdominal ultrasound and ascetic tap;

118 and bones/joints TB: X-ray, joint tap or synovial biopsy (NTP, 2015).

119 The regimen was prescribed on a category basis. The four treatment categories are as

120 follows: Category-I is new smear positive PTB $(\mathrm{PTB}+)$, severe forms of new extra-pulmonary

121 TB (EPTB), new severe concomitant HIV disease and TB meningitis. Category-II is previously

122 treated PTB+ (relapse, treatment after interruption and treatment failure). Category-III comprises

123 new smear negative PTB (PTB-) and less severe forms of EPTB. Category-IV includes chronic

124 and multidrug resistant TB (MDR-TB). The children diagnosed with $\mathrm{TB}$ always have an

125 intensive phase of 2 to 3 months and a continuation phase of 4 to 6 months. The anti-TB drugs

126 dosage depends on body weight and category of patient.

127 Treatment of children with TB aged $\leq 14$ years as per NTP is given in Table 1.. NTP 128 follows the treatment and dosage criteria as recommended by WHO (WHO, 2010). Patients 129 weighing $<5 \mathrm{~kg}$ are treated with individualized dosages while those weighing more than $30 \mathrm{~kg}$ 130 are treated using adult dosages.

131 According to the WHO (WHO, 2014), patients who were stated "cured" and/or had 132 "completed treatment" were termed as a "treatment success", and all those patients who had 133 defaulted, died, or experienced treatment failure were reported under the category of 134 "unsuccessful treatment". A cured patient was a bacteriologically confirmed PTB patient and 135 became smear negative in the last month of treatment and on at least one previous occasion. 
136 Treatment completed included TB patients who completed treatment with no record to show

137 smear negative in the last month of treatment and on at least one previous occasion.

138 Defaulters patients were those whose treatment was interrupted for 2 consecutive months or

139 more for any reason and failure patients were those whose sputum smear was positive at 5

140 months of treatment or later.

141 Data analysis

142 Data was entered and analysed using the Statistical Package for the Social Sciences (SPSS) for

143 Windows, version 24. Frequencies of categorical variables were generated by descriptive 144 statistical methods. Comparisons in categorical groups were performed using the chi-square test.

145 A logistic regression model was used to determine the predictors of unsuccessful outcome and 146 PTB. P values $<0.05$ were considered statistically significant.

147 RESULTS

\section{Proportion and trend of notification cases of childhood TB}

149 Figure 2 shows the proportion of childhood TB cases at the study site. During 2011 to 2015 , 150 childhood TB accounted 11.3\% (2167/19219) of all TB burden in 3 districts. The Proportion of

151 childhood TB ranged from $8.5 \%$ in 2011 to $18 \%$ in 2015 . In 2012, 2013 and 2014, the child

152

153

154

155

156

157

158

cases represented $8.5 \%, 8.8 \%$ and $9.9 \%$ respectively, of overall TB cases at the study site.

Differences in the proportion of childhood TB between the districts were observed, with the highest being in Jamshoro district and the lowest in the Matiari district.

A total of 2,167 patients meeting the inclusion criteria were enrolled in the study. In Hyderabad, childhood TB cases are registered at Sindh Government Hospital Qasimabad, Hyderabad (SGH-QH), Shah Bhitai Government Hospital, Latifabad, Hyderabad (SBGH-LH) and Liaquat University of Medical and Health Sciences Civil Hospital, Hyderabad (LUMHS- 
$159 \mathrm{CHH}$ ) where treatment is provided under the DOTS program. Among these three hospitals, the 160 maximum numbers of patients were registered in LUMHS-CHH (487) as compared to SBGH-

161 LH (136) and SGH-QH (52). Overall, the highest numbers of children with TB $(1,172)$ were

162 registered in the Institute of Chest Diseases Kotri, Sindh (ICDK) during the present study which 163 was almost 4 times the number of cases (320) registered at Syed Baqadar Shah Taluka Hospital, 164 Matiari (SBS-THM). The increased trend was observed from 2011 to 2015 in SBGH-LH and 165 ICDK. Conversely, in SGH-QH and LUMHS-CHH, the highest numbers of cases were reported 166 at the start of the study and then a steady decline was observed. For SBS-THM, the increasing 167 trend was seen from 2011 to 2014, and that dropped off in 2015.

168

169

170

171

172

173

174

175

176

177

178

179

180

181

\section{Trend of type of TB from 2011-2015}

Initially, the proportion of PTB- was $15.2 \%$ that declined to $14.7 \%$ in 2012 . A slight increase was noticed in the rate of PTB- (15.4\%) during 2013 that dropped to $14 \%$ in 2014 but then went up to $15.6 \%$ at the end of the period. Conversely, the proportion of PTB+ was low $(12.4 \%)$ during 2011 but then rose steadily to $13.4 \%$ and $14.2 \%$ in 2012 and 2013 , respectively. The rate of PTB+ subsequently descended from $12.7 \%$ in 2014 to $8.7 \%$ in 2015 . In terms of EPTB, the rate gradually climbed between 2011 and 2014 (21.2-29.2\%) (Fig. 3) and subsequently dropped to $18.7 \%$ at the end of study period.

\section{Demographic and clinical characteristics of patients}

Of the total 2,167 patients, $1,199(55.3 \%)$ were females and $968(44.7 \%)$ were males with a mean age of $7.4 \pm 4.4$ years. The majority of the children were aged between 11 to 14 years $(33 \%)$ followed by $28 \%$ in the age group of 6 to 10 years. Children aged 3 to 5 years were the smallest group comprising $17 \%$ of the total (Table 2). Baseline weight was documented for all patients and $75.2 \%$ of them were found to be underweight. Over three-quarter, $1,666(76.9 \%)$ of 
182 children were diagnosed with PTB. Of the total PTB cases, 331 (15.3\%) had PTB- and 221

183 (10.2\%) presented with PTB+. The remaining 1,114 (51.4\%) of PTB cases were those who had 184 no sputum examination (PTBNS). The majority $(91 \%)$ of PTB + were $\geq 9$ years with the 185 remaining $9 \%$ aged 7 to 8 years. In 501 cases of EPTB, peripheral lymphadenitis was the most 186 frequent (62.4\%) followed by $17.3 \%$ with abdominal TB (Table 2 ).

187 Concerning therapeutic categorization, 2,083 (96.1\%) were new cases (patients had either 188 received no ATT or received for $<1$ month in the past) and 84 (3.9\%) were cases of re-treatment 189 (those received ATT $>1$ month in the past). Of re-treatment cases, $9(10.7 \%)$ were registered as 190 relapse cases, $28(33.3 \%)$ were default, $14(16.7 \%)$ were failure and $33(39.3 \%)$ cases were 191 recorded as others. Similarly, 41 (48.8\%) presented with PTB+ and 20 (23.8\%) had PTB- while $19223(27.4 \%)$ were cases of EPTB.

\section{Risk factors of PTB}

194 In univariate analysis, variables which had statistically significant positive association with PTB 195 were being male (OR: 1.329, $\mathrm{p}=0.006)$, age group $\leq 2$ years (OR: 2.230, $\mathrm{p}<0.001)$ and patients documented as underweight (OR: $1.285, \mathrm{p}=0.029)$ with higher odd ratios comparatively to their

197

198

199

200

201

202

203

204 counterparts. There was no significant difference observed between rural and urban residents.

After adjusting for risk factors of PTB in univariate logistic regression, variables which were significantly associated with PTB in multivariate analysis were male (OR: 1.262, $\mathrm{p}=$ 0.029), children aged $\leq 2$ years (OR: 1.953, $\mathrm{p}<0.001)$ and those reported as underweight (OR:

$$
1.342, \mathrm{p}=0.008)(\text { Table } 3)
$$

\section{Treatment outcomes}

Among the 2,167 registered children, $56(2.6 \%)$ had no documented treatment outcomes. Of 97.4\% patients with documented treatment outcomes, $92.4 \%$ successfully completed treatment. 
205 There was no significant difference in the treatment success among male and female patients (p $206>0.05)$. Children aged 11 to 14 years had the lowest treatment success $(90.2 \%)$. The death rate 207 was higher among $\leq 2$ years $(2.4 \%)$ followed by age group 3 to 5 years with a death rate of $1 \%$ 208 (Table 4). The highest rate of default (5.6\%) and failure (2.3\%) was presented among those aged

20911 to 14 years. Female patients had a non-significantly increased rate of default compared to 210 male patients.

211 Patients from urban areas had the highest proportion of treatment success (94.7\%)

212 whereas the rate of failure, default, and death was high among rural and re-treated patients.

213 Correspondingly, among all sputum smear grading, +2 and +3 had lower treatment success rate.

214 Those suffering from EPTB were seen with more successful treatment outcomes relative to those 215 with PTB.

\section{Factors associated with unsuccessful treatment outcomes}

217 Table 5 presents the risk factors for unsuccessful treatment outcomes in logistic regression 218 analysis. In univariate analysis, age group 11 to 14 years (OR: 1.571, p $<0.001)$, rural residents 219 (OR: 2.101, $\mathrm{p}<0.001), \mathrm{PTB}+(\mathrm{OR}: 3.986, \mathrm{p}<0.001)$, underweight patients $(\mathrm{OR}: 1.581, \mathrm{p}=$ 2200.033 ) and retreated patients (OR: 7.962, $\mathrm{p}<0.001$ ), were observed as potential predictors of 221 unsuccessful treatment outcomes with higher odd ratios value.

222 In multivariate analysis, rural residents (OR: 2.146, p < 0.001), PTB+ (OR: 3.409, p < $2230.001)$ and re-treated patients (OR: 5.919, $\mathrm{p}<0.001$ ), were positively associated with 224 unsuccessful treatment outcomes with higher odd ratios.

\section{DISCUSSION}

226 The present study focused on describing the childhood TB treated under DOTS program in three 227 districts (Hyderabad, Jamshoro, and Matiari) of Sindh province, Pakistan. It reveals the common 
228 state of childhood TB support in these districts as the NTP is functioning in the same way

229 throughout the country at all health structures. To the best of our knowledge, this is the very first

230 study presenting epidemiological and clinical data together with clinical outcomes and risk

231 factors for TB in children conducted in the aforementioned districts.

232 In the present study, childhood TB represented $11.3 \%$ of all TB burden at the study site

233 between 2011 and 2015. This was lower than that reported in Tanzania (Mtabho et al., 2010).

234 During 2011, the highest proportion of child to adult cases was reported in SGH-QH while for

235 the years 2012 and 2013; LUMHS-CHH had the highest proportion. Additionally, in 2014 and

236 2015, SBS-THM contributed the highest number of childhood TB cases.

Patients aged $\leq 2$ years constituted $21.3 \%$ of total cases despite the fact that the risk of

238 TB is greatest in this age group (Marais et al., 2004). The highest cases of TB in the current

239 study were observed among the children aged 11 to 14 years $(33 \%)$ which is in agreement with

240 the previous studies conducted in Pakistan (Safdar et al., 2010) and Ethiopia (Hailu, Abegaz \&

241 Belay, 2014; Tilahun \& Gebre-Selassie, 2016). The most reasonable explanation can be

242 difficulties in the diagnosis of younger children, principally in collecting bacteriologic specimens

243 (Marais et al., 2006) or gastric aspirates (Planting et al., 2014; Zar et al., 2005) which can result

244 in under reporting of TB cases in this age group.. The notification rate of childhood TB was

245 higher in urban areas (57.3\%) than in rural areas, which conforms to a study from Northwest

246 Ethiopia (Tessema et al., 2009). The lower incidence rate in rural areas might possibly be due to

247 under-diagnosis or limited access to the treatment centres. In addition, this might be due to

248 illiteracy and lack of awareness of TB among caregivers/parents.

PTB was diagnosed in $76.9 \%$ of children, of which $221(13.3 \%)$ were bacteriologically 
251 numbers of PTB + cases among children are reported from India and Africa (Aketi et al., 2016;

252 Satyanarayana et al., 2010). Greater numbers of cases were diagnosed on clinical background as

253 they were unable to expectorate and techniques like induced sputum and gastric lavage to acquire

254 sputum among young children for smear microscopy are not frequently used at the study site.

255 The proportion of EPTB in the current study was $23.1 \%$. The proportion was parallel to the

256 studies conducted in other areas of Pakistan (Batra et al., 2012; Safdar et al., 2010) and Taiwan

257 (Tsai et al., 2013), but lower than that observed in Ethiopia (Hailu, Abegaz \& Belay, 2014) and

258 southern Taiwan (Cho et al., 2014). TB was slightly higher in female children (55.3\%) compared

259 to males (44.7\%). This finding is in line with previous studies (Sharma et al., 2008; Tilahun \&

260 Gebre-Selassie, 2016). Unfortunately, in some areas Pakistan, girls have an inferior status and

261 have limited rights, prospects and benefits of childhood than boys. At a very young age,

262 experiences of inequality are initiated for women and it is very difficult for them to overwhelm

263 this unfairness. In general, the girl gets less food, poorer access to education and less health care

264 than boys, particularly in families with a poor socio-economic background. A remarkable

265 proportion of the present study participants were underweight (75.2\%). According to WHO,

266 malnutrition is a pre-defined risk factor of TB in children i.e. children with TB are generally

267 found to be malnourished. Malnutrition is prevalent among all ages in Pakistan. Unfortunately,

268 one-third of children under 5 years old in Pakistan are reported underweight, 44\% as stunted and

269 15\% wasted (Das, Achakzai \& Bhutta, 2016). A high prevalence of malnourishment in patients

270 of the current cohort was a result of their socio-economic background.

271 Successful outcome is a marker of the quality of TB case management (WHO, 2014). The

272 overall TSR of $92.4 \%$ in the present study met the WHO target of $85 \%$. The TSR is higher than

273 the TSR reported in Malawi (Harries et al., 2002) and Botswana (Oeltmann et al., 2008) but 
274 lower than that reported in Delhi, India (Satyanarayana et al., 2010). Treatment outcomes were

275 recorded for 2,042 new cases and 69 re-treatment cases. There were 56 children for whom the

276 treatment record was not available. The death rate in this study $(1.0 \%)$ is comparable to that in

277 Punjab, Pakistan (Safdar et al., 2010) and India (Satyanarayana et al., 2010). In 2014, 1 million

278 new cases of childhood TB were estimated by WHO with 136,000 deaths at the proportion of

$27913.6 \%$ at the global level (Jenkins, 2016). However, the death rate in the present study was much

280 lower than death rates (3.3-17\%) previously reported elsewhere (Dangisso, Datiko \& Lindtjørn,

281 2015; Hailu, Abegaz \& Belay, 2014; Harries et al., 2002; Mtabho et al., 2010; Oeltmann et al.,

282 2008). The default rate (4.9\%) encompassed the foremost part of the unsuccessful outcome and

283 was higher than that (0.6-3.8\%) reported from other regions (Hailu, Abegaz \& Belay, 2014;

284 Satyanarayana et al., 2010; Tilahun \& Gebre-Selassie, 2016) but lower (7\%) than that informed

285 by Aketi et al., 2016.

286 In multivariate analysis, rural areas, sputum smear positivity, underweight, and re-

287 treatment were significantly associated with poor treatment outcomes. These findings are in line

288 with previous studies (Bloss et al., 2012; Jaganath \& Mupere, 2012; Sharma et al., 2008). The

289 most important reason for all these risk factors could be non-adherence due to lack of education

290 among the caregivers. Sindh is a multicultural province of Pakistan and is portrayed by an

291 extensive gap between rich and poor individuals with unequal access to education and health

292 services. Insufficient knowledge about TB and its treatment, longer distances to treatment centre

293 and associated costs affect patients' access to TB care and clinical outcomes result in treatment

294 delays and poor treatment outcomes. Moreover, children reported underweight were observed as

295 at a high risk of TB in the study area that signposted the poverty ratio and socioeconomic 
296 condition of the family that is an imperative issue for which instant steps need to be taken by the

297 authorities.

\section{Limitations of study}

299 The study has some limitations. Firstly, since the study was retrospective it was not possible to 300 collect socioeconomic data and adverse effects observed during the treatment. Factors like 301 family income and parents' education, that could affect the treatment outcomes were not 302 recorded and thus not examined. Secondly, features such as household size, household contacts 303 and nutritional status, which might serve as risk factors for childhood TB, were also not 304 documented.

\section{CONCLUSIONS}

306 In the present study, childhood TB represented $11.3 \%$ of all TB burden at the study site. The 307 treatment outcomes of childhood TB treated under the DOTS program in the study area was 308 satisfactory. The fairly high success rate could be due to enhanced case management with the 309 accessibility of free TB treatment and the promising performance of the DOTS strategy at the

310 health centres in study. Children aged $\leq 2$ years and male, living in rural areas, sputum smear 311 positive, underweight and those who are being re-treated may be given special attention as they 312 have a significant association with TB and poor treatment outcomes.

\section{Abbreviations}

314 AFB: Acid-Fast Bacilli; ATT: anti-tuberculosis treatment; AORs: adjusted odds ratios; COR: 315 crude odds ratios; CXR: chest X-ray; CIs: confidence intervals; DOTS: directly observed therapy 316 strategy; EPTB: extra-pulmonary TB; FNAC: Fine Needle Aspiration Cytology; Xpert 317 MTB/RIF: Gene Xpert MTB/RIF; ICDK: Institute of Chest Diseases Kotri, Sindh; LUMHS318 CHH: Liaquat University of Medical and Health Sciences Civil Hospital, Hyderabad; MTB: 319 Mycobacterium tuberculosis; NTP: National Tuberculosis Control Program; PTB: pulmonary 
320

321

322

323

324

325

326

327

328

329

330

331

332

333

334

335

336

337

338

339

340

341

342

343

344

345

346

347

348

349

350

351

352

TB; PTBNS: pulmonary TB with unknown sputum; PTB-: smear negative PTB; PTB+: smear

positive PTB; SBGH-LH: Shah Bhitai Government Hospital, Latifabad, Hyderabad; SBS-THM:

Syed Baqadar Shah Taluka Hospital, Matiari; SGH-QH: Sindh Government Hospital Qasimabad, Hyderabad; TB: tuberculosis; TST: Tuberculin skin test; WHO: World Health Organization.

\section{DECLARATIONS}

\section{Consent for publication}

Not applicable.

Availability of data and materials

The database used in this study is provided in the supplemental files. .

\section{REFERENCES}

Adams L, Olotu R, Talbot E, Cronin B, Christopher $\quad$ R, Mkomwa Z. 2014. Ending neglect: providing effective childhood tuberculosis training for health care workers in Tanzania. Public Health Action 4:233-237 DOI 10.5588/pha.14.0076.

Aketi L, Kashongwe Z, Kinsiona C, Fueza S, Kokolomami J, Bolie G, Lumbala P, Diayisu J. 2016. Childhood Tuberculosis in a Sub-Saharan Tertiary Facility: Epidemiology and Factors Associated with Treatment Outcome. PLoS One 11:e0153914 DOI 10.1371/journal.pone.0153914.

Akhtar S, Carpenter T, Rathi S. 2007. A chain-binomial model for intra-household spread of Mycobacterium tuberculosis in a low socio-economic setting in Pakistan. Epidemiology and Infection 135:27-33 DOI 10.1017/S0950268806006364.

Batra S, Ayaz A, Murtaza A, Ahmad S, Hasan R, Pfau R. 2012. Childhood Tuberculosis in Household Contacts of Newly Diagnosed TB Patients. PLoS One 7:e40880 DOI 10.1371/journal.pone.0040880.

Bloss E, Chan P, Cheng N, Wang K, Yang S, Cegielski P. 2012. Increasing directly observed therapy related to improved tuberculosis treatment outcomes in Taiwan. The International Journal of Tuberculosis and Lung Disease 16:462-467 DOI 10.5588/ijtld.11.0121.

Centers for Disease Control and Prevention NCfHS. 2001. Data Table of Weight-for-age Charts: Atlanta, USA, U.S. Department of Health \& Human Services HHS/Open USA.gov.

Cho Y, Ho T, Wang S, Shen C, Chuang P, Liu C. 2014. Childhood tuberculosis in southern Taiwan, with emphasis on central nervous system complications. Journal of Microbiology, Immunology and Infection 47:503-511 DOI 10.1016/j.jmii.2013.06.008. 
Dangisso M, Datiko D, Lindtjørn B. 2015. Low case notification rates of childhood tuberculosis in southern Ethiopia. BMC Pediatrics 15:1-10 DOI 10.1186/s12887-0150461-1.

Das J, Achakzai A, Bhutta Z. 2016. Stop stunting: Pakistan perspective on how this could be realized. Maternal \& Child Nutrition 12:253-256 DOI 10.1111/mcn.12285.

Dodd P, Yuen C, Sismanidis C, Seddon J, Jenkins H. 2017. The global burden of tuberculosis mortality in children: a mathematical modelling study. The Lancet. Global Health 5:e898-e906 DOI 10.1016/S2214-109X(17)30289-9.

Glaziou P, Falzon D, Floyd K, Raviglione M. 2013. Global epidemiology of tuberculosis. Seminars in Respiratory and Critical Care Medicine 34:3-16 DOI 10.1055/s-00321333467.

Hailu D, Abegaz W, Belay M. 2014. Childhood tuberculosis and its treatment outcomes in Addis Ababa: a 5-years retrospective study. BMC Pediatrics 14:1-7 DOI 10.1186/14712431-14-61.

Harries A, Hargreaves N, Graham S, Mwansambo C, Kazembe P, Broadhead R, Maher D, Salaniponi F. 2002. Childhood tuberculosis in Malawi: nationwide case-finding and treatment outcomes. The International Journal of Tuberculosis and Lung Disease 6:424431 DOI 10.5588/pha.12.0091.

Jaganath D, Mupere E. 2012. Childhood Tuberculosis and Malnutrition. The Journal of Infectious Diseases 206:1809-1815 DOI 10.1093/infdis/jis608.

Jenkins H. 2016. Global burden of childhood tuberculosis. Pneumonia 8:1-7 DOI 10.1186/s41479-016-0018-6.

Marais B, Gie R, Schaaf H, Hesseling A, Obihara C, Starke J, Enarson D, Donald P, Beyers N. 2004. The natural history of childhood intra-thoracic tuberculosis: a critical review of literature from the pre-chemotherapy era. The International Journal of Tuberculosis and Lung Disease 8:392-402.

Marais B, Hesseling A, Gie R, Schaaf H, Enarson D, Beyers N. 2006. The bacteriologic yield in children with intrathoracic tuberculosis. Clinical Infectious Diseases 42:e69-e71 DOI $10.1086 / 502652$.

Mtabho C, Irongo C, Boeree M, Aarnoutse R, Kibiki G. 2010. Childhood tuberculosis in the Kilimanjaro region: lessons from and for the TB programme. Tropical Medicine \& International Health 15:496-501 DOI 10.1111/j.1365-3156.2010.02481.x.

National TB Control Program. 2015. National Guidelines for the Managemnet of Tuberculosis in Pakistan. National TB control Programme, Ministry of Health, and Government of Pakistan. http://ntp.gov.pk/uploads/deskguide_for_Doctors.pdf.

Oeltmann J, Chengeta B, Mboya J, Wells C, Kilmarx P, Samandari T, Nelson L. 2008. Reported childhood tuberculosis treatment outcomes, Gaborone and Francistown, Botswana, 1998-2002. The International Journal of Tuberculosis and Lung Disease 12:186-192. 
393

394

395

396

397

398

399

400

401

402

403

404

405

406

407

408

409

410

411

412

413

414

415

416

417

418

419

420

421

422

423

424

425

426

427

428

429

430

431

432

Planting N, Visser G, Nicol M, Workman L, Isaacs W, Zar H. 2014. Safety and efficacy of induced sputum in young children hospitalised with suspected pulmonary tuberculosis. The International Journal of Tuberculosis and Lung Disease 18:8-12 DOI 10.5588/ijtld.13.0132.

Safdar N, Hinderaker S, Baloch N, Enarson D, Khan M, Morkve O. 2010. Diagnosis and outcome of childhood tuberculosis: implementing public health policy in three districts of Pakistan. The International Journal of Tuberculosis and Lung Disease 14:872-877.

Satyanarayana S, Shivashankar R, Vashist R, Chauhan L, Chadha S, Dewan P, Wares F, Sahu S, Singh V, Wilson N, Harries A. 2010. Characteristics and programme-defined treatment outcomes among childhood tuberculosis (TB) patients under the national TB programme in Delhi. PLoS One 5:e13338. DOI 10.1371/journal.pone.0013338.

Seddon J, Shingadia D. 2014. Epidemiology and disease burden of tuberculosis in children: a global perspective. Infection and Drug Resistance 7:153-165. DOI 10.2147/IDR.S45090.

Sharma S, Sarin R, Khalid U, Singla N, Sharma P, Behera D. 2008. The DOTS strategy for treatment of paediatric pulmonary tuberculosis in South Delhi, India. The International Journal of Tuberculosis and Lung Disease 12:74-80.

Tessema B, Muche A, Bekele A, Reissig D, Emmrich F, Sack U. 2009. Treatment outcome of tuberculosis patients at Gondar University Teaching Hospital, Northwest Ethiopia. A five-year retrospective study. BMC Public Health 9:1-8 DOI 10.1186/1471-2458-9-371.

Tilahun G, Gebre-Selassie S. 2016. Treatment outcomes of childhood tuberculosis in Addis Ababa: a five-year retrospective analysis. BMC Public Health 16:1-10 DOI 10.1186/s12889-016-3193-8.

Tsai K, Chang H, Chien S, Chen K, Chen K, Mai M, Chen K. 2013. Childhood tuberculosis: epidemiology, diagnosis, treatment, and vaccination. Pediatrics \& Neonatology 54:295302 DOI 10.1016/j.pedneo.2013.01.019.

World Health Oragnization. 2010. Rapid advice : treatment of tuberculosis in children. (WHO/HTM/TB/2010.13). Geneva, Switzerland.

World Health Oragnization. 2012. Global Tuberculosis Report. (WHO/HTM/TB/2012.6). Geneva, Switzerland.

World Health Oragnization. 2014. Guidance for national tuberculosis programmes on the management of tuberculosis in children. (WHO/HTM/TB/2014.03). Geneva, Switzerland.

World Health Oragnization. 2015. Global Tuberculosis Report. (WHO/HTM/TB/2015.22). Geneva, Switzerland.

World Health Oragnization. 2017. Global Tuberculosis Report. (WHO/HTM/TB/2017.23). Geneva, Switzerland.

Zar H, Hanslo D, Apolles P, Swingler G, Hussey G. 2005. Induced sputum versus gastric lavage for microbiological confirmation of pulmonary tuberculosis in infants and young children: a prospective study. The Lancet 365:130-134 DOI 10.1016/S01406736(05)17702-2. 


\section{Table 1 (on next page)}

Dosage of first-line anti-TB drugs for children based on NTP and WHO. 


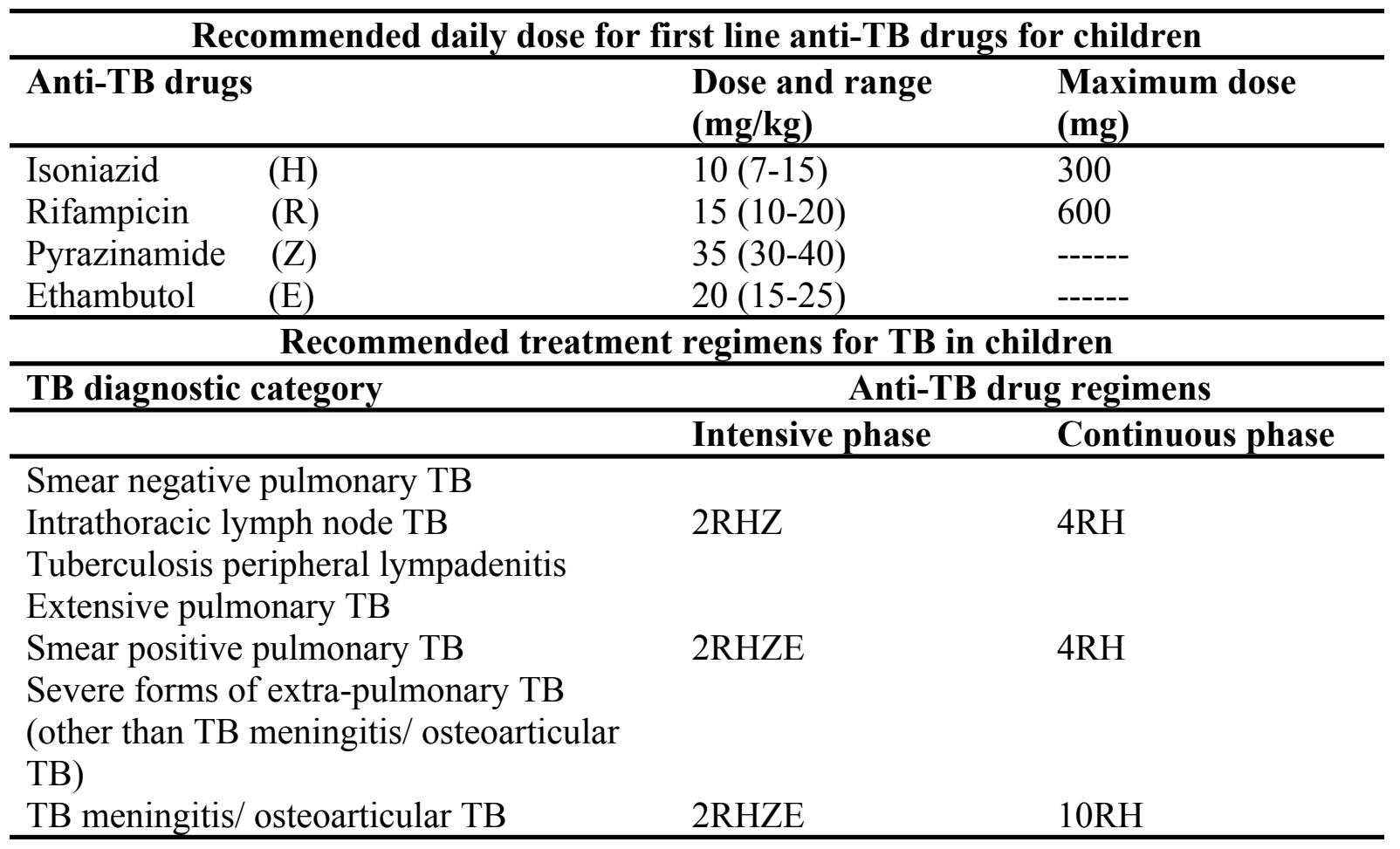




\section{Table 2 (on next page)}

Socio-demographic and baseline clinical characteristics of children with TB in studied hospitals $(n=2,167)$.

PTB-, smear negative pulmonary TB; PTB+, smear positive pulmonary TB; PTBNS, pulmonary TB with unknown sputum; EPTB, extra-pulmonary TB; Underweight*, ‘ 5 percentiles; **, relapse, default and failure cases. 


\begin{tabular}{|c|c|}
\hline Variables & Frequency (\%) \\
\hline \multicolumn{2}{|l|}{ Gender } \\
\hline Male & $968(44.7)$ \\
\hline Female & $1,199(55.3)$ \\
\hline \multicolumn{2}{|l|}{ Age (years) } \\
\hline$\leq 2$ & $461(21.3)$ \\
\hline $3-5$ & $384(17.7)$ \\
\hline $6-10$ & $607(28)$ \\
\hline $11-14$ & $715(33)$ \\
\hline \multicolumn{2}{|l|}{ Residence } \\
\hline Rural & $925(42.7)$ \\
\hline Urban & $1242(57.3)$ \\
\hline \multicolumn{2}{|l|}{ Type of TB } \\
\hline Smear positive PTB $(\mathrm{PTB}+)$ & $221(10.2)$ \\
\hline Smear negative PTB (PTB-) & $331(15.3)$ \\
\hline PTB with unknown smear (PTBNS) & $1,114(51.4)$ \\
\hline ЕРТВ & $501(23.1)$ \\
\hline \multicolumn{2}{|l|}{ EPTB site } \\
\hline Peripheral Lymph nodes & $313(62.5)$ \\
\hline Abdominal & $87(17.4)$ \\
\hline Pleural & $32(6.4)$ \\
\hline Miliary & $21(4.2)$ \\
\hline Bones/Joints & $19(3.8)$ \\
\hline Meningitis & $4(0.8)$ \\
\hline Skin & $3(0.6)$ \\
\hline Others & $22(4.4)$ \\
\hline \multicolumn{2}{|l|}{ Weight (percentiles) } \\
\hline Underweight* & $1,629(75.2)$ \\
\hline Normal weight & $538(24.8)$ \\
\hline \multicolumn{2}{|l|}{ Registration category } \\
\hline New & $2,083(96.1)$ \\
\hline Retreated $^{* *}$ & $84(3.9)$ \\
\hline
\end{tabular}




\section{Table 3(on next page)}

Logistic regression analysis for predictors of PTB $(n=1666)$. 


\begin{tabular}{|c|c|c|c|c|c|c|}
\hline \multirow[t]{2}{*}{ Characteristics } & \multicolumn{2}{|c|}{ PTB } & \multicolumn{2}{|c|}{ Univariate analysis } & \multicolumn{2}{|c|}{ Multivariate analysis } \\
\hline & Yes $n(\%)$ & No $n(\%)$ & $\operatorname{COR}(95 \% \mathrm{CI})$ & p-value & $\operatorname{AOR}(95 \% \mathrm{CI})$ & p-value \\
\hline \multicolumn{7}{|l|}{ Gender } \\
\hline Male & $771(79.7)$ & $197(20.4)$ & $1.329(1.08-1.62)$ & 0.006 & $1.262(1.02-1.55)$ & 0.028 \\
\hline Female & $895(74.6)$ & $304(25.4)$ & $0.752(0.61-0.92)$ & & $0.792(0.64-0.97)$ & \\
\hline \multicolumn{7}{|l|}{ Age (years) } \\
\hline$\leq 2$ & $399(86.6)$ & $62(13.4)$ & $2.230(1.67-2.97)$ & $<0.001$ & $1.953(1.36-2.79)$ & $<0.001$ \\
\hline $3-5$ & $296(77.1)$ & $88(22.9)$ & $1.014(0.78-1.31)$ & 0.971 & 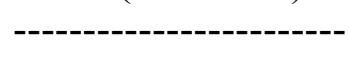 & ----------- \\
\hline $6-10$ & $451(74.3)$ & $156(25.7)$ & $0.921(0.66-1.22)$ & 0.050 & $0.868(0.64-1.17)$ & 0.356 \\
\hline $11-14$ & $520(72.8)$ & $195(27.3)$ & $0.712(0.57-0.87)$ & 0.001 & $0.820(0.61-1.09)$ & 0.181 \\
\hline \multicolumn{7}{|l|}{ Residence } \\
\hline Rural & $715(77.3)$ & $210(22.7)$ & $1.042(0.85-1.27)$ & 0.691 & . & ----------- \\
\hline Urban & $951(76.6)$ & $291(23.4)$ & $0.960(0.78-1.17)$ & & & \\
\hline \multicolumn{7}{|c|}{ Weight (percentiles) } \\
\hline Underweight & $1271(78)$ & $358(22)$ & $1.285(1.02-1.60)$ & 0.029 & $1.342(1.06-1.68)$ & 0.008 \\
\hline Normal & $395(73.4)$ & $143(26.6)$ & $0.778(0.62-0.97)$ & & $0.745(0.59-0.93)$ & \\
\hline
\end{tabular}


Table 4(on next page)

Treatment outcomes of patients as per national guidelines $(n=2111)$.

PTB-, smear negative pulmonary TB; PTB+, smear positive pulmonary TB; PTBNS, pulmonary TB with unknown sputum; EPTB, extra-pulmonary TB. 


\begin{tabular}{|c|c|c|c|c|c|c|c|c|}
\hline Characteristics & $\begin{array}{l}\text { Cured } \\
n=144 \\
(6.8 \%)\end{array}$ & $\begin{array}{l}\text { Completed } \\
n=1806 \\
(85.6 \%) \\
\end{array}$ & $\begin{array}{l}\text { Failed } \\
n=19 \\
(0.9 \%)\end{array}$ & $\begin{array}{l}\text { Default } \\
n=104 \\
(4.9 \%)\end{array}$ & $\begin{array}{l}\text { Died } \\
n=22(1 \%)\end{array}$ & $\begin{array}{l}\text { Transferred } \\
\text { out } \\
n=16(0.8 \%)\end{array}$ & $\begin{array}{l}\text { Total cases } \\
\text { evaluated } \\
2111(\%) \\
\end{array}$ & $\overline{p-v a l u e}$ \\
\hline \multicolumn{9}{|l|}{ Gender } \\
\hline Male & $56(5.9)$ & $827(87.1)$ & $4(0.4)$ & $44(4.6)$ & $13(1.4)$ & $6(0.6)$ & $950(45)$ & 0.092 \\
\hline Female & $88(7.6)$ & $979(84.3)$ & $15(1.3)$ & $60(5.2)$ & $9(0.8)$ & $10(0.9)$ & $1,161(55)$ & \\
\hline \multicolumn{9}{|l|}{ Age (years) } \\
\hline $0-2$ & 00 & $421(92.3)$ & 00 & $23(5)$ & $11(2.4)$ & $1(0.2)$ & $456(21.6)$ & $<0.001$ \\
\hline $3-5$ & 00 & $345(93.3)$ & $2(0.5)$ & $16(4.3)$ & $4(1)$ & $3(0.8)$ & $370(17.5)$ & \\
\hline $6-10$ & $31(5.3)$ & $523(89.2)$ & $1(0.2)$ & $26(4.4)$ & $2(0.3)$ & $3(0.5)$ & $586(27.8)$ & \\
\hline $11-14$ & $\begin{array}{l}113 \\
(16.2)\end{array}$ & $517(74)$ & $16(2.3)$ & $39(5.6)$ & $5(0.7)$ & $9(1.3)$ & $699(33.1)$ & \\
\hline \multicolumn{9}{|l|}{ Residence } \\
\hline Rural & $61(6.8)$ & $744(82.6)$ & $10(1.1)$ & $68(7.5)$ & $11(1.2)$ & $7(0.8)$ & $901(42.7)$ & $<0.001$ \\
\hline Urban & $83(6.9)$ & $1,062(87.8)$ & $9(0.7)$ & $36(3)$ & $11(0.9)$ & $9(0.7)$ & $1,210(57.3)$ & \\
\hline \multicolumn{9}{|c|}{ Weight (percentiles) } \\
\hline Underweight & $120(7.5)$ & $1,343(84.1)$ & $18(1.1)$ & $85(5.3)$ & $19(1.2)$ & $11(0.7)$ & $1,596(75.6)$ & 0.017 \\
\hline Normal weight & $24(4.7)$ & $463(89.9)$ & $1(0.2)$ & $19(3.7)$ & $3(0.6)$ & $5(1)$ & $515(24.4)$ & \\
\hline \multicolumn{9}{|l|}{ Type of TB } \\
\hline PTB- & 00 & $302(93.8)$ & $1(0.3)$ & $17(5.3)$ & $2(0.6)$ & 00 & $322(15.3)$ & $<0.001$ \\
\hline PTB + & $144(66)$ & $29(13.3)$ & $15(6.9)$ & $22(10.1)$ & $2(0.9)$ & $6(2.8)$ & $218(10.3)$ & \\
\hline PTBNS* & 00 & $1,019(93.8)$ & $3(0.3)$ & $42(3.9)$ & $14(1.3)$ & $8(0.7)$ & $1,086(51.4)$ & \\
\hline ЕРТВ & 00 & $456(94)$ & 00 & $23(4.8)$ & $4(0.8)$ & $2(0.4)$ & $485(23)$ & \\
\hline \multicolumn{9}{|c|}{ Registration Category } \\
\hline New & $130(6.4)$ & $1,776(87)$ & $14(0.7)$ & $96(4.7)$ & $15(0.8)$ & $11(0.5)$ & $2042(96.7)$ & $<0.001$ \\
\hline Retreated & $14(20.3)$ & $30(43.5)$ & $5(7.2)$ & $8(11.6)$ & $7(10.1)$ & $5(7.2)$ & $69(3.3)$ & \\
\hline
\end{tabular}


Table 5(on next page)

Univariate analysis of risk factors for unsuccessful treatment outcomes $(n=2,111)$.

PTB-, smear negative pulmonary TB; PTB+, smear positive pulmonary TB; PTBNS, pulmonary TB with unknown sputum; EPTB, extra-pulmonary TB. 


\begin{tabular}{|c|c|c|c|c|c|c|}
\hline \multirow[t]{2}{*}{ Characteristics } & \multirow{2}{*}{$\begin{array}{l}\text { Treatment } \\
\text { success } \\
n(\%)\end{array}$} & \multirow{2}{*}{$\begin{array}{l}\text { Treatment } \\
\text { failure } \\
n(\%)\end{array}$} & \multicolumn{2}{|l|}{ Univariate analysis } & \multicolumn{2}{|c|}{ Multivariate analysis } \\
\hline & & & COR (95\% CI) & p-value & AOR (95\% CI) & p-value \\
\hline \multicolumn{7}{|l|}{ Gender } \\
\hline Male & $883(93)$ & $67(7)$ & $0.861(0.62-1.19)$ & 0.369 & ------------------------ & ---------- \\
\hline Female & $1,067(92)$ & $94(8)$ & $1.161(0.83-1.60)$ & & & \\
\hline \multicolumn{7}{|l|}{ Age (years) } \\
\hline$\leq 2$ & $421(92.3)$ & $35(7.7)$ & $1.00(0.68-1.49)$ & 0.960 & ------------------------ & ------- \\
\hline $3-5$ & $345(93.2)$ & $25(6.8)$ & $0.856(0.55-1.33)$ & 0.487 & ----------------------- & ------ \\
\hline $6-10$ & $554(94.5)$ & $32(5.5)$ & $0.625(0.41-0.93)$ & 0.021 & $0.545(0.33-0.88)$ & 0.015 \\
\hline $11-14$ & $630(90.2)$ & $69(9.8)$ & $1.571(1.13-2.17)$ & $<0.001$ & $0.817(0.49-1.33)$ & 0.421 \\
\hline \multicolumn{7}{|l|}{ Residence } \\
\hline Rural & $805(89.5)$ & $96(10.5)$ & $2.101(1.51-2.91)$ & $<0.001$ & $2.146(1.53-3.00)$ & $<0.001$ \\
\hline Urban & $1,145(94.5)$ & $65(5.5)$ & $0.476(0.34-0.66)$ & & $0.481(0.34-0.67)$ & \\
\hline \multicolumn{7}{|l|}{ Type of TB } \\
\hline $\mathrm{PTB}^{-}$ & $302(93.8)$ & $20(6.2)$ & $0.774(0.47-1.25)$ & 0.302 & ------------------------ & ---------- \\
\hline $\mathrm{PTB}^{+}$ & $173(79.4)$ & $45(20.6)$ & $3.986(2.73-5.81)$ & $<0.001$ & $3.409(2.11-5.48)$ & $<0.001$ \\
\hline PTBNS* & $1,019(93.8)$ & $67(6.2)$ & $0.653(0.47-0.90)$ & 0.010 & $1.072(0.68-1.68)$ & 0.762 \\
\hline ЕРТВ & $456(94)$ & $29(6)$ & $0.727(0.47-1.09)$ & 0.126 & ----------------------- & ---------- \\
\hline \multicolumn{7}{|c|}{ Weight (percentiles) } \\
\hline Underweight & $1,463(91.7)$ & $133(8.3)$ & $1.581(1.03-2.40)$ & $\mathbf{0 . 0 3 3}$ & $1.441(0.91-2.23)$ & 0.102 \\
\hline Normal weight & $487(94.6)$ & $28(5.4)$ & $0.632(0.41-0.96)$ & & $0.694(0.44-1.07)$ & \\
\hline \multicolumn{7}{|c|}{ Registration category } \\
\hline New & $1,906(93.7)$ & $136(6.3)$ & $0.125(0.07-0.21)$ & $<0.001$ & $0.17(0.09-0.30)$ & $<0.001$ \\
\hline Retreated & $44(60.7)$ & $25(39.3)$ & $7.962(4.73-13.40)$ & & $5.919(3.36-10.40)$ & \\
\hline
\end{tabular}




\section{Figure 1}

NTP flow chart for assessment of a child with suspected TB.

*Negative TST does not rule out TB, evaluate further if strongly suspected. **prolong illness

like cough, fever, weight loss, abdominal mass, lymphadenopathy and history of contact with

TB case in family. ***Absence of above. 


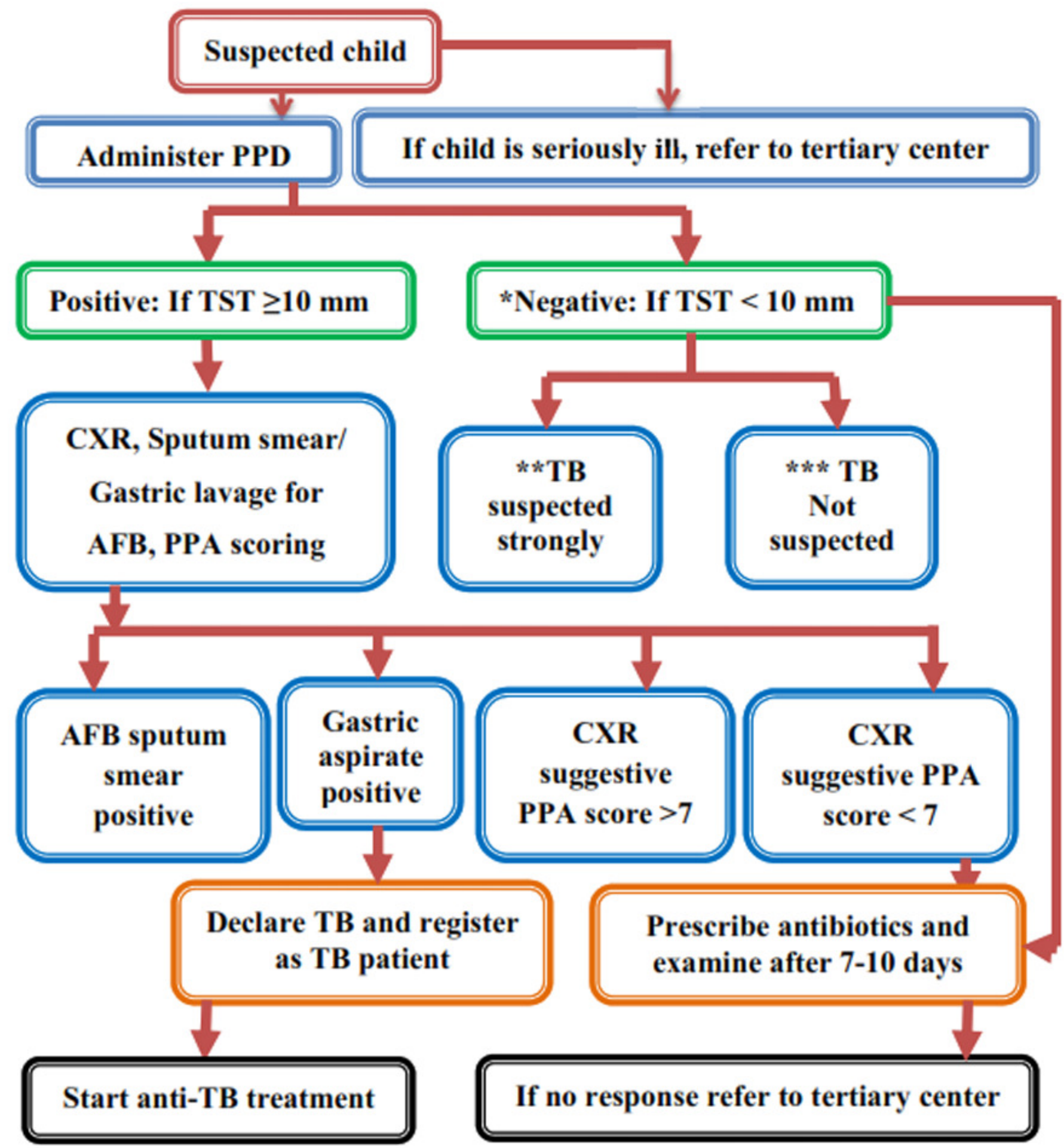




\section{Figure 2}

Proportion of childhood TB burden in five hospitals (2011-2015).

SBGH-LH, Shah Bhitai Government Hospital, Latifabad, Hyderabad; SGH-QH, Sindh Government Hospital Qasimabad, Hyderabad; LUMHS-CHH, Liaquat University of Medical and Health Sciences Civil Hospital Hyderabad; SBS-THM, Syed Baqadar Shah Taluka Hospital, Matiari; ICDK, Institute of Chest Diseases Kotri, Sindh. The figure shows of childhood TB cases in all five hospitals. The trend varied greatly for all these hospitals during study time. SBGH-LH and ICDK had maximum cases in 2015. For SGH-QH highest cases were noted during 2011, LUMHS-CHH in 2012 and for SBS-THM in 2014.

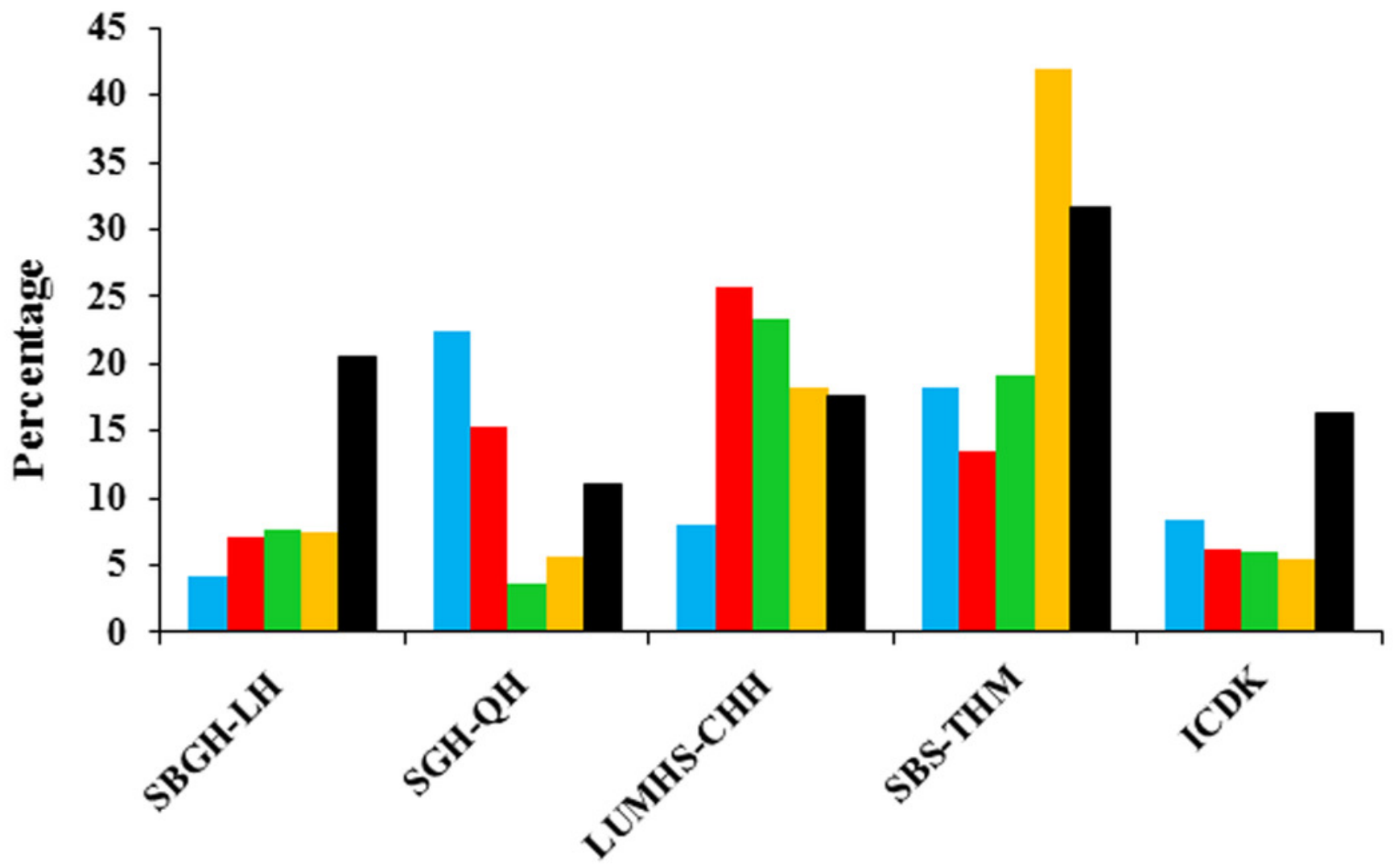

$2011 \square 2012 \square 2013 \square 2014 \square 2015$ 


\section{Figure 3}

Trend of type of TB during five years of study.

PTB-, smear negative pulmonary TB; PTB+, smear positive pulmonary TB; EPTB, extrapulmonary TB. Trend of different types of TB were noticed for children from 2011 to 2015. There was a slight variability was seen for PTB-. The maximum fluctuation was observed for EPTB starting from $21.2 \%$ reaching up to $29.8 \%$ and then finally declining to $18.7 \%$. A decreasing trend was seen for PTB+ among children.

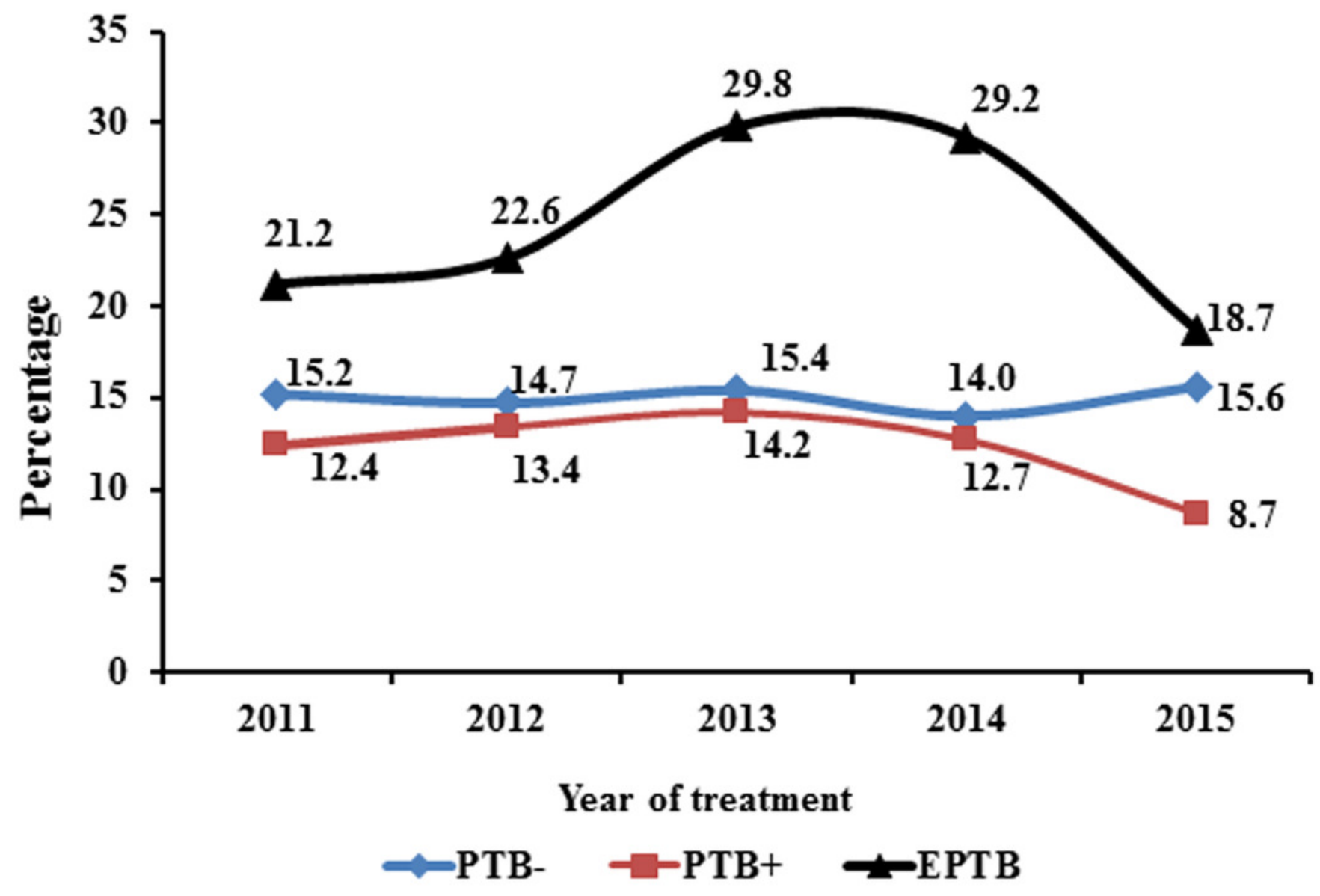

